\title{
Myths and Mates in Childbearing Depression
}

\author{
Valerie E. Whiffen
}

SUMMARY. Many myths exist about postpartum depression (PPD), all of which are based on the assumption that PPD differs qualitatively from depression that occurs at other times in women's lives. These myths paint a misleading picture of how PPD arises and may prevent women from receiving treatment for their difficulties. In this article, I identify five common myths and review the research literature to demonstrate that each lacks an empirical basis. Next, I present a model based on attachment theory, which I use to conceptualize PPD that occurs in the context of relationship distress. Finally, I illustrate this model with a clinical case. [Article copies available for a fee from The Haworth Document Delivery Service: 1-800-HAWORTH. E-mail address: <docdelivery@haworthpress.com> Website: <http://www.HaworthPress. com> (c) 2004 by The Haworth Press, Inc. All rights reserved.]

KEYWORDS. Postpartum depression, attachment, marital distress

Valerie E. Whiffen, PhD, is Professor in the School of Psychology and Director of the APA-accredited Training Clinic at the University of Ottawa. She has published widely in the area of depression, with a particular focus on the causes of women's depression. She is a registered clinical psychologist, and has a small private practice for the treatment of depression and marital distress.

Address correspondence to: Valerie E. Whiffen, School of Psychology, University of Ottawa, Ottawa, ON K1N 6N5, Canada (E-mail: whiff@uottawa.ca).

[Haworth co-indexing entry note]: "Myths and Mates in Childbearing Depression." Whiffen, Valerie E. Co-published simultaneously in Women \& Therapy (The Haworth Press, Inc.) Vol. 27, No. 3/4, 2004, pp. 151-164; and: From Menarche to Menopause: The Female Body in Feminist Therapy (ed: Joan C. Chrisler) The Haworth Press, Inc., 2004, pp. 151-164. Single or multiple copies of this article are available for a fee from The Haworth Document Delivery Service [1-800-HAWORTH, 9:00 a.m. - 5:00 p.m. (EST). E-mail address: docdelivery@haworthpress.com].

http://www.haworthpress.com/store/product.asp?sku=J015

(C) 2004 by The Haworth Press, Inc. All rights reserved. 
What the laws of Texas have failed to realize is that pregnancy and birth involve one of the most massive physiological change[s] a human can experience. Motherhood is unique given the incredible flux of reproductive hormones related to birth and the postpartum period. For some, these hormones lead to severe depression and psychosis. To say "Andrea Yates is sick and dangerous" simply ignores the existence of these reproductive flows which can bring feelings of great warmth and love in some, but also oppressive irrational thoughts and acts in others. (Press release issued by Postpartum Support International, March 15, 2002)

The Andrea Yates case catapulted postpartum depression (PPD) onto the front pages of North American newspapers. It happens every time a young mother murders her infant. Often, as is true in this case, the children do not need even to be infants for the mother's behavior to be explained by PPD. The press release quoted above makes reference to many of the myths about depression that is related to childbirth. One of the primary myths adopted by medical professionals and promulgated by the media is that PPD is caused by biological factors, particularly hormones (Martinez, Johnston-Robledo, Ulsh, \& Chrisler, 2000), a myth that persists despite the lack of evidence for a direct link. Collectively these myths create a picture of PPD that is at best misleading and at worst an impediment to effective treatment. However, medical professionals and the media are not the only ones who subscribe to these myths; their power is such that women with PPD often believe the myths themselves.

The myths all assume that PPD is different from nonchildbearing depression. However, a review of the research literature indicates that PPD has not been differentiated from depression that occurs at other points in women's lives. Similar to other episodes of depression, PPD often is associated with relationship difficulties. ${ }^{1}$ In the second part of this article, I present a model of PPD that occurs in the context of relationship distress, which I illustrate with an example from my clinical work. Throughout the article, I highlight the implications of research and theory for psychotherapists who work with PPD women.

\section{THE MYTHS OF POSTPARTUM DEPRESSION}

\section{Myth \#1: Recently Delivered Women Are at Risk for PPD}

The press release says it bluntly: Hormones associated with pregnancy and delivery cause childbearing women to be uniquely susceptible to depression. In popular press articles, hormones are cited more frequently than any other potential cause (Martinez et al., 2000). What is the empirical support for this assertion? Despite the persistence of hormonal explanations in the medical and 
lay literatures, there is surprisingly little evidence to support the role of hormones in the etiology of CBD. Some women experience CBD as a result of thyroid problems (Harris et al., 1989). However, no other hormonal causes have been identified consistently, despite decades of research on this topic.

Women are more prone to depression during childbearing periods than at other times in their lives. Approximately $13 \%$ of women who recently gave birth experience depressive symptoms severe enough to warrant a diagnosis of depression, which is a significant increase over the rate normally found among women of childbearing age (cf. Whiffen, 1992). However, to make sense of this number we need to distinguish prevalence from incidence. Prevalence rates refer to the total number of cases identified in the postpartum period regardless of when the episodes started, whereas incidence rates refer only to those cases that began after delivery. This distinction is critical because the label "postpartum depression" implies that the depression started after the partum event. However, studies that follow women from pregnancy show that as many as $40 \%$ of the episodes that are present after the birth also were present during the pregnancy (Whiffen, 1992). Researchers rarely make this distinction or attempt to date the onset of the episode. Thus, a depressive episode that is detected after childbirth could have begun at any time before, during, or after pregnancy, and therefore may or may not be related to having a baby.

The term "postpartum depression" is misleading because it implies that the depression is related causally to having a baby. This mislabeling can lead clinicians to misunderstand the nature of their client's depressive episodes. In recognition of this problem, I prefer the more descriptive term "childbearing depression" (CBD), which makes no assumptions about when the episode started. Using this term also reminds me as a clinician that, in trying to understand a childbearing woman's depression, I need to take into account not only her entire pregnancy but also the context in which she became pregnant. I am careful to investigate the possibility that the pregnancy is irrelevant to the depression.

\section{Myth \#2: \\ PPD Is Qualitatively Different from Other Forms of Depression}

Some people argue that the symptoms of PPD are different from those of depression that occurs at other times, that women with PPD are more anxious and agitated, that they are obsessed with thoughts of harming their babies, or that they are at risk for infanticide. The specific connection between PPD and infanticide is made frequently in the popular press (Martinez et al., 2000). Groups that promote the study and treatment of PPD believe that they are more likely to get funding if they can make the case that PPD is a disorder to which childbearing women are uniquely susceptible. Admitting that PPD is not special may leave these women untreated, as are most women who experience depression (Hunsley, Lee, \& Aubry, 1999). Although it is vital to obtain services 
for women with PPD, the argument that PPD is a unique disorder is a double-edged sword because it fosters the perception, widely held among medical professionals and in the media, that PPD is hormonal and self-correcting.

Is PPD different from other forms of depression? It is interesting that when CBD and depressed but nonchildbearing women are compared, there are few differences (Whiffen \& Gotlib, 1993). CBD women tend to be less severely depressed than nonchildbearing depressed women, with an average score on the Beck Depression Inventory in the mild to moderate range. Less than half of the depressed women diagnosed in research studies meet criteria for Major Depression; the majority meet criteria for an Adjustment Disorder with Depressed Mood or Minor Depression. However, the types of symptoms they report, the courses of their episodes, and their scores on such psychosocial variables as coping and social support are indistinguishable from those of nonchildbearing depressed women. Thus, CBD typically is mild but does not seem to differ qualitatively from depression that occurs at other times, at least on the variables assessed by researchers to date. The major implication of this finding is that working with CBD women should be no different from working with women who are depressed at other times in their lives. Effective treatments for depression also should be effective for $\mathrm{CBD}$, and the underlying causes of the depression should be basically the same.

\section{Myth \#3: PPD Does Not Need to Be Treated}

Many medical professionals agree with the assertion that hormones cause CBD. Furthermore, they believe that women's mood will self-correct as their hormones return to pre-pregnancy levels. This perception may be part of the reason that most women do not receive treatment for CBD (Cox, Connor, \& Kendell, 1982), although it is not clear that childbearing depressed women are any less likely to receive treatment than are nonchildbearing depressed women. However, in the absence of a hormonal explanation for CBD, there is no reason to believe that episodes remit spontaneously. Half of the episodes detected at 1 month postpartum are still present 5 months later, a recovery rate that does not differ from that for depressed but nonchildbearing women (Whiffen \& Gotlib, 1993).

Perhaps CBD doesn't need to be treated because it is typically mild? Although the symptoms are mild, CBD is not a trivial disorder. Women who experience $\mathrm{CBD}$ are at risk for subsequent depressive episodes, both after pregnancy and at other times in their lives (Bagedahl-Strindlund \& Ruppert, 1998). Between one-quarter and one-half of the women who experience an episode of CBD will have a depressive episode after a subsequent pregnancy (Cooper \& Murray, 1995; Marks, Wieck, Checkley, \& Kumar, 1996; Wisner et al., 2001). The median age of onset for a first episode of depression is 26 years (Burke, Burke, Regier, \& Rae, 1990), which is close to the average age of 28 at which women in Western societies have their first children. Thus, 
CBD may be the first episode of depression in the life of a woman who is vulnerable. This makes it an important episode to treat because the risk of relapse increases with each episode experienced (Teasdale et al., 2000).

An episode of depression at this point in a woman's life also can have en-

during consequences for the infant and for the vitality of the woman's relationship with her partner. The infants of CBD women develop more slowly, and they cry more and are more difficult to soothe than the infants of nondepressed women (Beck, 1998; Whiffen \& Gotlib, 1989b). It is not surprising that they also are less likely to form secure attachments to their mothers (Atkinson et al., 2000). Developmental psychologists believe that attachment security is a cornerstone of social and emotional adjustment in childhood. Thus, the infants of CBD women are at risk for emotional difficulties themselves. Finally, women who experience CBD continue to report lower levels of marital satisfaction 5 years later (Nettelbladt, Uddenberg, \& Englesson, 1985). Thus, an episode of CBD can be associated with serious and long-lasting consequences for the woman as well as her family. Although the depressive symptoms may appear to be mild, because of its timing CBD often has a cascading impact on women's lives.

\section{Myth \#4:}

PPD Occurs Suddenly to Otherwise Emotionally Healthy Women

Some writers describe CBD as a disorder that descends mysteriously and unpredictably from the heavens, a view that often is shared by the women who experience it. This impression simply is not supported by research. The best predictors of a new episode of PPD are a history of emotional problems and depression levels during pregnancy (O'Hara \& Swain, 1996; Whiffen, 1992). The majority of women who develop CBD have sought help for emotional problems in the past, and they report higher levels of emotional distress during pregnancy than do women who do not develop CBD. Women also are more likely to become depressed when they experience during the childbearing period significant life stress that may or may not be related to pregnancy and/or to infant care (cf. Swendsen \& Mazure, 2000). These are the same factors that are implicated in the onset of nonchildbearing depression (O'Hara, Schlechte, Lewis, \& Varner, 1991), which lends further support to the lack of a distinction between CBD and other forms of depression.

The interpersonal context in which a woman lives also is a significant determinant of whether or not she will develop CBD. Women are more vulnerable if they believe that their childhood relationships with their parents lacked warmth or were explicitly rejecting (Gotlib, Whiffen, Wallace, \& Mount, 1991). Among children, parental rejection is associated with the development of insecure attachment (Ainsworth, Blehar, Waters, \& Wall, 1968), which may be a risk factor for adult depression (Whiffen, Kallos-Lilly, \& MacDonald, 2001). Lack of social support, particularly lack of concrete help provided by 
the baby's father, also contributes to CBD (O'Hara \& Swain, 1996). Lack of support may be an expression of marital distress, which is another reliable predictor of CBD (O'Hara \& Swain, 1996; Whiffen, 1992). In one study, the husbands of women who went on to experience CBD were rated by interviewers during pregnancy as showing greater indifference toward their wives (Marks et al., 1996). They were not more critical or hostile, but they were more detached and less invested in their wives' pregnancies. Research with nonchildbearing depressed women indicates that husbands' indifference maintains or exacerbates wives' depression over time (Whiffen et al., 2001). In my clinical experience, women perceive husbands who are emotionally detached and unwilling to help with the care of a new baby as unloving. This attribution may be particularly painful if the woman believes that her parents rejected her as well.

\section{Myth \#5: Only Women Experience PPD}

The implication that depression follows from a "partum" event, as well as the tendency to consider PPD a unique or hormonal disorder, leads most researchers to overlook the data that show that fathers of new babies also experience emotional distress. Men do not have a "partum" event, so they cannot develop PPD per se. Nonclinical studies show that having a baby is measurably more disruptive for fathers than it is for mothers. Although mothers' scores on measures of emotional distress and marital dissatisfaction return to their prepartum levels by one year postpartum, fathers' scores continue to indicate distress (Vandell, Hyde, Plant, \& Essex, 1997). Three to nine percent of new fathers meet diagnostic criteria for an Axis I disorder, especially depression or anxiety (Ballard, Davis, Cullen, Mohan, \& Dean, 1994), which is much higher than the usual rate for men of this age (e.g., Regier et al., 1988). In one sample of men whose wives already were diagnosed with depression, 1 in 4 of the husbands also met criteria for an Axis I disorder (Zelkowitz \& Milet, 1996).

These findings are important even to a clinician who works exclusively with women because most childbearing women have an ongoing relationship with their baby's father. A depressed or anxious husband is likely to have a negative impact on his wife. When husbands are depressed, they tend to feel unhappy in their marriages. Husbands' marital distress tends to make their wives unhappy as well (Thompson, Whiffen, \& Blain, 1995; Whiffen \& Gotlib, 1989a), and a woman's marital dissatisfaction is a strong predictor of her subsequent experience of an episode of major depression (Whisman, 1999). In addition, the high rate of paternal diagnosis when mothers are depressed suggests that maternal depression may be a marker of a distressed system. Thus, it is important to consider the system that provides the immediate context for childbearing depression when treating these women. 


\section{WHAT IS CHILDBEARING DEPRESSION?}

If CBD is not what the myths say it is, then what is it? So far, I have used the research to counteract the picture of CBD that is widely endorsed by medical professionals and promoted by the media (Martinez et al., 2000). Can we read between the lines of these studies to get a picture of what CBD is? Before doing so, it is important to emphasize that CBD is just as heterogeneous as depression that occurs at other times. One woman became depressed because her father developed terminal cancer shortly after she became pregnant. She passed her pregnancy worrying that he would die before she could give birth to her baby, his first grandchild. When he died 2 months after the birth, she plunged into a deep bereavement. Another woman became depressed when she had a little girl. Her first baby was a boy, and she experienced no depression related to that pregnancy. When her little girl was born she was reminded of the sexual abuse that she had experienced throughout her childhood. She grieved for her daughter's vulnerability to sexual victimization, and for her own abuse, which she had never processed. These vignettes show that there are as many causes of CBD as there are causes of nonchildbearing depression.

That having been said, the research does suggest certain patterns. The typical woman who experiences CBD is emotionally vulnerable. She feels rejected by one or both parents. She is unhappy in her romantic relationship and may fear that her partner does not really love her. She feels unsupported by her partner. Perhaps her partner does not help out around the house or with taking care of other children. Outsiders may see her partner as indifferent to her, and this indifference is likely to maintain her feelings of depression. These factors would (and do) induce depression at any point in a woman's life. Feminist theories maintain that women's self-concept and self-esteem are embedded in the context of their significant relationships (Miller, 1986). When women are able to maintain close and harmonious relationships with the people who are important to them, they feel good about themselves. Conversely, relationships that are disconnected or conflicted promote the development of low self-esteem and depression (Jack, 1991). I maintain that this process is heightened during childbearing periods. Pregnancy makes a woman especially vulnerable to relationship distress because the baby is a tangible manifestation of her commitment to her partner, and she will be sensitive to any indication that this commitment is not shared.

Attachment theory provides an interpersonal framework for conceptualizing and treating CBD when it occurs in the context of relationship distress (Whiffen \& Johnson, 1998). Attachment theory developed originally as a description of infant-caregiver relationships. In the past 15 years, it has been extended to the study of romantic relationships, and it is now being applied to the treatment of clinical problems in couples and families (cf. Johnson \& Whiffen, in press). Attachment theory proposes that both one's sense of self and one's beliefs about the availability and emotional responsiveness of others are determined by the quality of key relationships (Bowlby, 1969, 1973). As children 
we learn that we are lovable and that others are reliable and responsive to our needs by having parents or other attachment figures who treat us warmly and who demonstrate interest in and concern for us. Needs to feel connected to and accepted by significant others are not manifestations of dependency but basic human needs that are present throughout the lifespan. In Western societies where nuclear families predominate, the romantic partner is the primary attachment figure for most adults (Bartholomew, 1990; Hazan \& Shaver, 1987). Partners who are warm and emotionally available mirror an image of ourselves as lovable and worthy, whereas those who are cold, critical, and disengaged reflect back a picture of ourselves as unlovable, defective, and unworthy. When our interactions with attachment figures tell us that we are unlovable or unimportant, we become distressed. We still attempt to meet our needs for connection and validation in our close relationships. However, when these relationships are distressed, our attempts may take maladaptive forms that inadvertently maintain or exacerbate emotional distress.

Attachment needs become particularly salient during transitions, which bring uncertainty and change and which prompt us to turn to attachment figures for reassurance (Bowlby, 1973). The introduction of a new child into an existing couple or family is a transition that can have dramatic consequences for couples' attachment security (Whiffen \& Johnson, 1998). The birth of the first child has special implications for attachment because couples must relinquish their exclusive pair bond to become a family. First time mothers also want to feel good about their mothering, and they typically look to their partners for feedback about how well they are doing. A critical or unsupportive partner can undermine women's developing self-efficacy in the maternal role. Thus, for first time parents, the birth of a child has an impact both on their relationship and on the woman's sense of self. However, even couples with other children may find that the addition of a new baby creates emotional distance or challenges the mother's ability to cope. The way that a couple handles the birth of their children is an important test of their ability to remain emotionally available and responsive to one another under stressful conditions.

When individuals are stressed, they normally turn to an attachment figure for reassurance and comfort. According to the theory, this is one of the primary purposes served by attachment figures. In stressful circumstances, couples that are securely attached turn to one another and provide the reassurance that each person is seeking (cf. Johnson \& Whiffen, 1999). Although securely attached couples may encounter difficulties associated with childbearing, they should be able to use their relationship to cope with stress and to regulate the associated negative affect. Thus, partners who have proven to one another in the past that they are emotionally available and responsive during periods of crisis should be relatively resilient to CBD. However, couples that have failed previous tests of their emotional availability will encounter difficulties. These failed tests may be "attachment injuries" (Johnson, Makinen, \& Millikin, 2001) from a previous time in the relationship that have never been resolved. The birth of a 
new child also may trigger attachment fears in an individual who experienced disappointment and unavailability earlier in life with other figures. For instance, a woman who believes that her parents left her to fend for herself as a child may expect her partner to do the same.

Attachment insecurity takes one of two basic forms. Individuals who are anxiously attached to their romantic partners look to them frequently for reassurance because they believe they are unlovable. They are thought to have experienced inconsistency with attachment figures previously, which has left them vigilant to signs that they might be abandoned. Paradoxically, research shows that they tend to seek reassurance by blaming and criticizing their partners, in part because they have difficulty containing their high levels of negative emotion (cf. Johnson \& Whiffen, 1999). This interpersonal coping strategy increases relationship conflict, which is strongly predictive of subsequent depression (Whisman, 1999).

Individuals who are fearfully attached to their romantic partners want to be close but fear that they will be rejected, a dilemma that they resolve by maintaining emotional distance even in their close relationships. When stressed, they tend to withdraw emotionally and physically from their partners (cf. Johnson \& Whiffen, 1999). This interpersonal coping strategy may indicate that the individual is already on the road to depression; Bowlby (1980) considered giving up on the attachment figure to be the first step in the development of depression. This strategy also may create a self-fulfilling prophesy. Partners may not recognize fearfully attached individuals' distress and therefore neglect to provide the needed support. Partners' failure to provide support will confirm fearful individuals' perception that partners are unresponsive. This perception is likely to contribute to feelings of depression. Research with nonchildbearing couples indicates that fearful attachment is especially associated with depression when a fearful woman has a dismissing romantic partner or spouse (Whiffen et al., 2001). Dismissing individuals are thought to protect their self-esteem from the damaging effects of rejection by denying that attachment needs are important. Dismissing husbands are likely to be unaware of wives' distress and need for support and to respond insensitively to those bids for reassurance that they do recognize.

Depression is the most common form of emotional distress that women experience during childbearing periods. Bowlby (1980) linked sadness and depression specifically to loss and disappointment. The potential for loss and disappointment during childbearing periods is substantial despite cultural pressure to view the birth of a child as a joyful event that marks the beginning of a new life (Nicolson, 1998). Although the event is a beginning for the infant, it may be an ending for the parents. The transition from romantic couple to working partnership may be unexpected or come too early in the relationship for first time parents. The mother may stop working outside the home and have to give up not only the work role but also the social support and self-efficacy that work provides. Even a woman who previously stayed at home with small children may feel her life is suddenly constrained by a baby who has medical 
problems or who cries frequently. Change always is accompanied to some degree by loss. It is important for therapists to keep the idea of loss in mind when working with childbearing women because clients may believe that they are not entitled to experience and express feelings of loss about the beginning of their child's life.

\section{Clinical Case}

Annie was a professional woman in her 30 s who had been married for about 18 months when she became pregnant. Her husband, Rob, was a U.S. citizen who had been unable to obtain a work permit in Canada, with the result that he had been unemployed for more than a year when I first saw her.

She was the third child in a family of five. Her mother was a stay-at-home mom who developed a terminal illness and died when Annie was an adolescent. Her father was a workaholic who was harshly critical of his children. Annie reported a weak attachment to her mother whom she perceived as overwhelmed by looking after her children. Even as a child, Annie was quick to withdraw from relationships if she felt hurt, angry, or disappointed. As an adult, she felt distant in her relationships with men. She said that she cultivated this distance, both because she found men's emotional demands overwhelming and because she was afraid of being hurt. Being married to Rob was a relief at first because he demanded very little emotional intimacy. In attachment terms, Annie reported a fearful style, and she described Rob as dismissing.

When Annie was approximately 7 months pregnant, she and Rob went on a canoeing trip with several other couples. On the second day, Annie fell and broke her wrist. Rob took her back to the base lodge, got her medical attention, bought her some novels, then announced that he was finishing the trip and would return in 5 days. Annie was devastated. This trip became an attachment injury to which Annie returned repeatedly during therapy. She believed that Rob's behavior reflected his lack of investment in her pregnancy. The incident had an extra emotional kick for her because the basis of their relationship was doing physical activities together. There was little emotional intimacy, and they had few common intellectual interests; Annie feared that without the glue of shared outdoor activities he would eventually find someone who was "more fun to play with." Through our work on this incident, Annie realized that she wanted to feel like a family with Rob instead of feeling like "separate checks."

When the baby was born, Annie's belief that he was not invested in her or the baby intensified because she saw him "carrying on with his life as if nothing (has) changed." She believed that she and the baby were unimportant to Rob and that eventually he would leave them both. She was aware of "shoring up her defenses" in preparation for this loss. For instance, she would not let him help in any way with the care of their child. She told me that she was afraid that if she put down part of her burden and let him pick it up, it would be too heavy to pick up again when he finally left her. By this time she was severely depressed. 
In couples therapy we explored how Rob felt about becoming a father, and his behavior was immediately comprehensible: He was angry with Annie for getting pregnant. He thought that they had not been married long enough, and he wanted to be employed before becoming a father. They had one conversation about getting pregnant during which he expressed his feelings clearly, but Annie decided that he would change his mind once he became a father, and she stopped using birth control without telling him. Once she was pregnant, Rob thought that there was no point to repeatedly expressing his anger and disappointment. However, he could not embrace a decision that he had not made.

Rob's and Annie's attachment styles were compatible as long as they could lead relatively independent lives. Once they needed to become interdependent, neither believed that the other could be counted upon to be emotionally available and responsive. Annie felt unsupported and deserted by Rob, even though she reported that his behavior did not change much before and after the baby's birth. In fact, it was the lack of change when change was normative and expected that led her to believe that he was not invested in her pregnancy and their child. In Bowlby's terms, Annie's depression was linked to her loss of Rob when he failed to make the transition to parent with her. Rob thought that he had been treated as a "sperm bank." He also lost Annie in that she completely disregarded what he wanted, which led him to question how much she really cared for him as a person and how much he was just a "bit player" in her life.

\section{CONCLUSION}

The myths of PPD are all premised on the assumption that PPD is unique and different from nonchildbearing depression. However, a review of the research literature indicates that it is just like depression that occurs at other times in women's lives. Like nonchildbearing depression, the causes of CBD are varied, but a significant proportion of CBD women experience relationship difficulties. Relationship distress is depressing because most women's self-esteem is heavily invested in their ability to maintain close, harmonious relationships with the people who are important to them. The childbearing period may be one of particular vulnerability because it is a time when women normally expect to feel close to and supported by their romantic partners. A partner's disengagement at this time may be particularly demoralizing. As illustrated in the clinical case, when CBD co-occurs with relationship distress, couples therapy is the treatment of choice. However, couples therapy may be unacceptable to nondepressed partners who have difficulty seeing the relevance of their relationship to their partners' depression (Emanuels-Zuurveen \& Emmelkamp, 1996). In these situations, an attachment framework used within the context of individual therapy can help women with CBD to understand how specific relationship difficulties may be driving their depression. 


\section{NOTE}

1. Although all of the empirical literature to date has examined heterosexual women in co-habiting relationships, most of whom were married to the baby's father, there is no reason to assume that the conceptualization of PPD that I present here would not apply also to women in lesbian relationships and possibly even to single mothers.

\section{REFERENCES}

Ainsworth, M., Blehar, M., Waters, E., \& Wall, S. (1968). Patterns of attachment: A psychological study of the strange situation. Hillsdale, NJ: Erlbaum.

Atkinson, L., Paglia, A., Coolbear, J., Niccols, A., Parker, K. C. H., \& Guger, S. (2000). Attachment security: A meta-analysis of maternal mental health correlates. Clinical Psychology Review, 20, 1019-1040.

Bagedahl-Strindlund, M., \& Ruppert, S. (1998). Parapartum mental illness: A long-term follow-up study. Psychopathology, 31, 250-259.

Ballard, C. G., Davis, R., Cullen, P. C., Mohan, R. N., \& Dean, C. (1994). Prevalence of postnatal psychiatric morbidity in mothers and fathers. British Journal of Psychiatry, 164, 782-788.

Bartholomew, K. (1990). Avoidance of intimacy: An attachment perspective. Journal of Personal and Social Relationships, 7, 147-178.

Beck, C. T. (1998). The effects of postpartum depression on child development: A meta-analysis. Archives of Psychiatric Nursing, 12, 12-20.

Bowlby, J. (1969). Attachment and loss Vol. 1: Attachment. New York: Basic Books.

Bowlby, J. (1973). Attachment and loss Vol. 2: Separation, anxiety, and anger. New York: Basic Books.

Bowlby, J. (1980). Attachment and loss Vol. 3: Loss. New York: Basic Books.

Burke, K., Burke, J., Regier, D., \& Rae, D. (1990). Age of onset of selected mental disorders in five community populations. Archives of General Psychiatry, 47, 511-518.

Cooper, P. J., \& Murray, L. (1995). Course and recurrence of postnatal depression: Evidence for the specificity of the diagnostic concept. British Journal of Psychiatry, $166,191-195$.

Cox, J., Connor, Y., \& Kendell, R. (1982). Prospective study of the psychiatric disorders of childbirth. British Journal of Psychiatry, 140, 111-117.

Emanuels-Zuurveen, L., \& Emmelkamp, P. M. G. (1996). Individual behavioural-cognitive therapy v. marital therapy for depression in maritally distressed couples. British Journal of Psychiatry, 169, 181-188.

Gotlib, I. H., Whiffen, V. E., Wallace, P. M., \& Mount, J. H. (1991). A prospective investigation of postpartum depression: Factors involved in onset and recovery. Journal of Abnormal Psychology, 100, 122-132.

Harris, B., Fung, H., Johns, S., Kologlu, M., Bhatti, R., McGregor, A. M., Richards, C. J., \& Hall, R. (1989). Transient post-partum thyroid dysfunction and postnatal depression. Journal of Affective Disorders, 17, 243-249. 
Hazan, C., \& Shaver, P. (1987). Romantic love conceptualized as an attachment process. Journal of Personality and Social Psychology, 52, 511-524.

Hunsley, J., Lee, C. M., \& Aubry, T. (1999). Who uses psychological services in Canada? Canadian Psychology, 40, 232-240.

Jack, D. C. (1991). Silencing the self: Women and depression. Cambridge, MA: Harvard University Press.

Johnson, S. M., Makinen, J. A., \& Millikin, J. W. (2001). Attachment injuries in couples: A new perspective on impasses in couples therapy. Journal of Marital and Family Therapy, 27, 145-155.

Johnson, S. M., \& Whiffen, V. E. (1999). Made to measure: Adapting emotionally focused couples therapy to partners' attachment styles. Clinical Psychology: Science \& Practice, 6, 366-381.

Johnson, S. M., \& Whiffen, V. E. (in press). Attachment: A guide for couple and family interventions. New York: Guilford.

Marks, M., Wieck, A., Checkley, S., \& Kumar, C. (1996). How does marriage protect women with histories of affective disorder from post-partum relapse? British Journal of Medical Psychology, 69, 329-342.

Martinez, R., Johnston-Robledo, I., Ulsh, H. M., \& Chrisler, J. C. (2000). Singing "the baby blues": A content analysis of popular press articles about postpartum affective disturbances. Women \& Health, 31, 37-56.

Miller, J. B. (1986). Toward a new psychology of women. Boston: Beacon Press.

Neddelbladt, P., Uddenberg, N., \& Englesson, I. (1985). Marital disharmony four and a half years postpartum. Acta Psychiatrica Scandinavica, 71, 392-401.

Nicolson, P. (1998). Postnatal depression: Psychology, science and the transition to motherhood. New York: Routledge.

O’Hara, M. W., Schlechte, J. A., Lewis, D. A., \& Varner, M. W. (1991). Controlled prospective study of postpartum mood disorders: Psychological, environmental, and hormonal variables. Journal of Abnormal Psychology, 100, 1-11.

O’Hara, M. W., \& Swain, A. M. (1996). Rates and risks of postpartum depression: A meta-analysis. International Review of Psychiatry, 8, 37-54.

Regier, D., Boyd, J., Burke, J., Rae, D., Myers, J., Kramer, M., Robins, L., George, L., Karno, M., \& Locke, B. (1988). One month prevalence of mental disorders in the United States. Archives of General Psychiatry, 45, 977-986.

Swendsen, J. D., \& Mazure, C. M. (2000). Life stress as a risk factor for postpartum depression: Current research and methodological issues. Clinical Psychology: Science and Practice, 7, 17-31.

Teasdale, J. D., Segal, Z. V., Williams, J. M. G., Ridgeway, V. A., Soulsby, J. M., \& Lau, M. A. (2000). Prevention of relapse/recurrence in major depression by mindfulness-based cognitive therapy. Journal of Consulting and Clinical Psychology, 68, 615-623.

Thompson, J. M., Whiffen, V. E., \& Blain, M. D. (1995). Depressive symptoms, sex, and perception of intimate relationships. Journal of Social and Personal Relationships, 12, 49-66. 